\title{
Experimental and FE Modeling Investigation of Spot Welded Thin Steel Sheets
}

\author{
Miroslav ŽIVKOVIĆ, Marina VUKOVIĆ, Vukić LAZIĆ, Vladimir MILOVANOVIĆ, Vladimir DUNIĆ, Dražan KOZAK, Dragan RAKIĆ
}

\begin{abstract}
The spot welded thin steel sheets specimens are experimentally and numerically examined in this paper. The two specimens are joined using Resistance Spot Welding (RSW) method. The spot-welded joints consist of three zones with different material properties. Change of material properties during the welding process is caused by mechanical and thermal loading. The mechanical properties of thin steel sheets are determined by several tension tests. The specimens are cut in three different directions regarding a rolling direction of the basic material plate. Shear resistance of the spot welded joints is experimentally examined on the universal testing machine by displacement-controlled tensile loading tests. The numerical analysis is performed by large-strain plasticity theory implemented into a Finite Element Method based software. Comparison of the Finite Element (FE) modeling and experimental results verifies the proposed stress integration algorithm and modeling technique as powerful tools for prediction of the spot-welded joint behavior.
\end{abstract}

Keywords: finite element method; large-strain plasticity; resistance spot welding; thin steel sheets; welding parameters

\section{INTRODUCTION}

Spot-welded (SW) joints are widely used in steel sheet welding, especially in the automotive industry [1]. It is essential to simulate the behavior of the SW joints because of the significant influence on construction integrity. The factors which influence the joints behavior are mechanical properties of the basic material, joint geometry, properties of different welded zones, steel sheet thickness, procedures and parameters of welding.

Various experimental [2] and numerical procedures [3] for the prediction of the behavior of various types of SW joints were developed. Several simplified finite element (FE) models with different mesh refinements were used for modeling of SW joints in [4]. The evaluation of their performance showed that the proposed models have good agreement with experimental results. In [5], the influences of the heat-affected zone (HAZ) on the welded joints behavior were recognized as very significant. The initial stress field in welded specimens was numerically analyzed in [6] using the three-point bending test. The decrease of stress levels is captured ahead of the crack tip. The stress field was determined by the crack position. Properties of different weld zones of SW joints are considered in [7]. The numerical modeling, indentation and hardness test were used to discover the hardening parameters of the weld base zone, HAZ region and nugget zone. Simulated stressstrain results for primary material were compared with the experimental tensile loading tests. In [8], the primary material of steel sheets is modeled by shell elements, contact elements by gap elements and SW joints by beam elements.

In this paper, the mechanical properties of thin steel sheets are determined using several strained specimens cut in three different directions regarding a rolling direction. Determined properties are tensile strength, yield stress, Young modulus, and hardening factors. Welding of specimens is done using the recommended parameters of the diameter of the electrode contact surface, the electric current of welding, the welding time and the electrode forces. Optimal welding parameters are chosen after the visual control of defects (inclusions, porous) and mechanical and metallographic testing of the welded joints. Experimental results are compared with the results obtained by FE modeling of SW joints. The 3D elements with incompatible modes are used with the determined material parameters in different material zones. Largestrain plasticity model implemented in Finite Element Method (FEM) based PAK software for structural analysis [9] was used for numerical simulation. The obtained results verify good functionality of the proposed large-strain algorithm for the suggested FE model of SW joints.

\section{RESISTANCE SPOT WELDING (RSW)}

SW is a sort of electrical resistance welding. The amount of released heat in the conducting wire during the welding time, necessary for the welding process, can be calculated as [10]:

$Q=k \int_{0}^{t} R i^{2} \mathrm{~d} t$,

where the utility factor is $k$, the electric current of welding is $i$, the electrical resistance is $R$ and the elapsed time is $t$. The utility factor $k$ defines the amount of effective energy spent during the welding process.

The RSW parameters are diameter of the electrode contact surface $d_{\mathrm{e}}$, electric current of welding $I_{\mathrm{w}}$, welding time $t_{\mathrm{w}}$, and electrode force $F_{\mathrm{w}}$. There is an experimental recommendation for the best adjusting of those parameters [11]. After the initial set of parameters, additional fine corrections are considered depending on the results of uniaxial tension tests on the universal testing machine (Fig. 1). Maximum breakout force of a joint, core diameter, macro- and micro- structure and hardness of welded joint are taken as the control criteria. Since the thickness of the steel sheets in those experiments is $s=0,8 \mathrm{~mm}$, adopted parameters are given in Tab. 1.

\section{MECHANICAL CHARACTERISTICS}

A quality of a SW joint depends on the characteristics of the base material (BM) such as strength, hardness, level of cold processing, and surface conditions. The uniaxial tensile tests are done with the experimental specimens (Fig. 2) made of a low-carbon steel. The tests were conducted on 
a computer-controlled Zwick/Roell Z100 universal testing machine with a displacement-controlled loading rate of $10 \mathrm{~mm} / \mathrm{min}$. The steel chemical composition of the primary material is listed in Tab. 2.

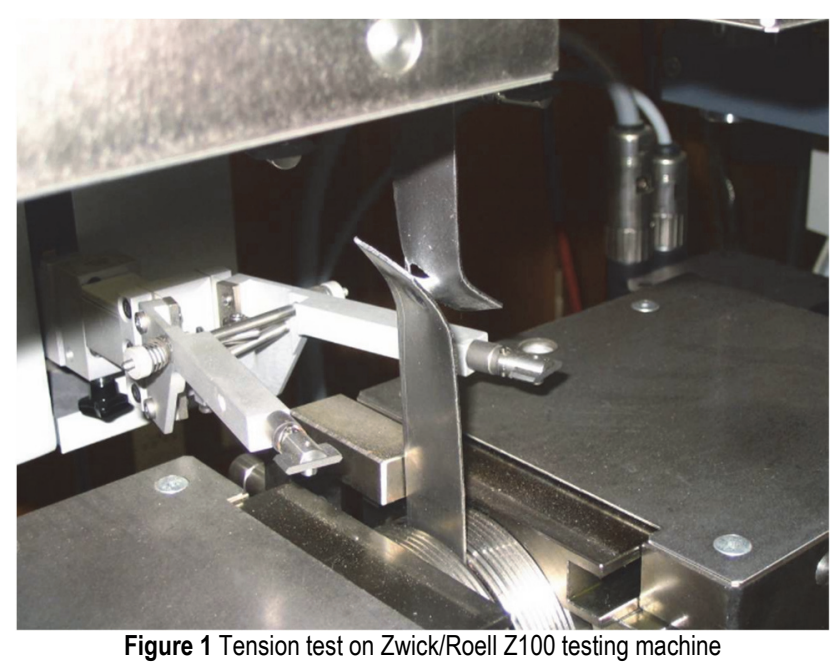

Table 1 Parameters of resistance spot welding

\begin{tabular}{|c|c|c|c|c|c|}
\hline $\begin{array}{c}\text { Thickness } \\
\text { s } / \mathrm{mm}\end{array}$ & $d_{\mathrm{e}} / \mathrm{mm}$ & $I_{\mathrm{w}} / \mathrm{A}$ & $t_{\mathrm{w}} / \mathrm{s}$ & $F_{\mathrm{w}} / \mathrm{N}$ & $F_{\mathrm{r}} / \mathrm{N}$ \\
\hline 0.80 & 5,5 & 6600 & 0,28 & 1250 & 4300 \\
\hline
\end{tabular}

Table 2 Chemical composition of steel sheet
\begin{tabular}{|c|c|c|c|}
\hline Element & Carbon & Phosphorus & Sulfur \\
\hline$\%$ & 0,1 & 0,05 & 0,05 \\
\hline
\end{tabular}

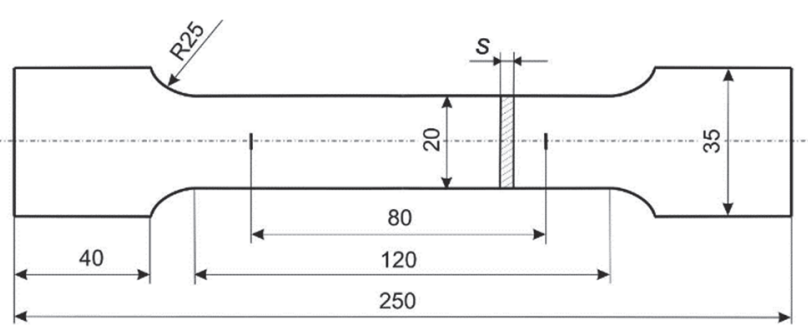

Figure 2 Testing specimen - shape and dimensions

The specimens are cut from the steel sheet stock in three directions: in the direction of sheet rolling $\left(0^{\circ}\right)$, under $45^{\circ}$ to the direction of sheet rolling, under $90^{\circ}$ to the direction of sheet rolling. The reason for those experiments is standard checking of unequal properties (anisotropy) in different orientation angles [12]. The anisotropy is taken into consideration using the average value of the property:

$X=\frac{X_{0^{\circ}}+2 X_{45^{\circ}}+X_{90^{\circ}}}{4}$.

The measured properties and the average results are given in Tab. 3 .

Table 3 Mechanical characteristics of steel sheet test specimens

\begin{tabular}{|c|c|c|c|c|}
\hline Angle & $R_{\mathrm{p}} / \mathrm{MPa}$ & $R_{\mathrm{m}} / \mathrm{MPa}$ & $n /-$ & $E / \mathrm{GPa}$ \\
\hline $0^{\circ}$ & 179,1 & 305,1 & 0,20367 & 185,3 \\
\hline $45^{\circ}$ & 193,5 & 314,9 & 0,19553 & 207,2 \\
\hline $90^{\circ}$ & 187,6 & 302,3 & 0,19433 & 194,5 \\
\hline$X_{\text {avg }}$ & 188,4 & 309,3 & 0,19716 & 198,5 \\
\hline
\end{tabular}

The most proper analytical approximations [13] for hardening functions for soft steels and aluminum alloys are:

$K=C \varphi^{n}$, where $C=R_{\mathrm{m}} \frac{e^{n}}{n^{n}}$,

$K=C_{1}+C_{2} \varphi^{n}$, where $C_{1}=R_{\mathrm{p}}$,

$C_{2}=\frac{R_{\mathrm{m}} e^{n}-R_{\mathrm{p}}}{n^{m}} ; m=\frac{R_{\mathrm{m}} e^{n}}{R_{\mathrm{m}} e^{n}-R_{\mathrm{p}}} n$,

$K=C_{3}+C_{4} \varphi$, where $C_{3}=R_{\mathrm{m}} e^{n}(1-n) ; C_{4}=R_{\mathrm{m}} e^{n}$,

where $K$ is the deformation resistance, $R_{\mathrm{m}}$ is the ultimate strength, $R_{\mathrm{p}}$ is the yield strength, $n$ is the hardening coefficient and $\varphi$ is the effective plastic strain.

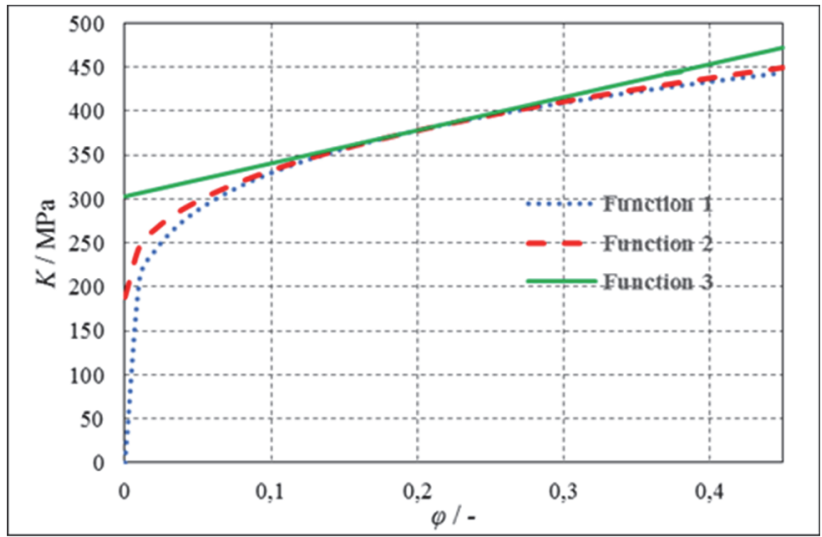

Figure 3 Hardening functions for average values of mechanical parameters

For the average values given in Tab. 3, the hardening functions (Eqs. (3)-(5)) are:

$$
\begin{aligned}
& K=518,8 \cdot \varphi^{0,19716}, \\
& K=188,4+357,3 \cdot \varphi^{0,39454}, \\
& K=302,4+376,7 \cdot \varphi,
\end{aligned}
$$

for thickness of sheet $0,8 \mathrm{~mm}$. Graphical representation of hardening functions is given in Fig. 3. Function 1 ((Eq. (6)) is represented with the dotted line, Function 2 ((Eq. (7)) with the dashed line and Function 3 ((Eq. (8)) using the continuous line.

\section{STRESS INTEGRATION ALGORITHM}

The stress integration procedure for large-strain plasticity theory is implemented into the PAK software for structural analysis [9]. The basic assumption in the largestrain theory is that the total strain gradient ${ }_{0}^{t+\Delta t} \boldsymbol{F}$ is expressed using Jacobian matrices $\boldsymbol{J}$ as:

${ }_{0}^{t+\Delta t} \boldsymbol{F}={ }^{t+\Delta t} \boldsymbol{J}^{T}{ }^{0} \boldsymbol{J}^{-T}$,

and multiplicative decomposition as:

$$
{ }_{0}^{t+\Delta t} \boldsymbol{F}={ }^{t+\Delta t}{ }_{\tau}^{E}{ }_{0}^{\tau} \boldsymbol{F}^{P},
$$


where ${ }^{t+\Delta t} \boldsymbol{F}^{E}$ is the elastic and ${ }_{0}^{\tau} \boldsymbol{F}^{P}$ is the plastic strain gradients. The trial elastic strain gradient ${ }_{\tau}^{t+\Delta t} \boldsymbol{F}_{*}^{E}$ at the end of the time step is:

$$
{ }_{\tau}^{t+\Delta t} \boldsymbol{F}_{*}^{E}={ }_{0}^{t+\Delta t} \boldsymbol{F}{ }_{\tau}^{0} \boldsymbol{F}^{P} .
$$

The isotropic plasticity von Mises material model is used. Computational steps $[9,14]$ for stress integration of isotropic material are given in Tab. $4,{ }_{t}^{t+\Delta t} \boldsymbol{F}$ is relative strain gradient, ${ }_{0}^{t+\Delta t} \bar{\lambda}_{k}^{E}$ and ${ }^{t+\Delta t} \overline{\boldsymbol{p}}_{k}^{E}$ are the principal stretches and principal directions of ${ }_{\tau}^{t+\Delta t} \overline{\boldsymbol{B}}_{*}^{E}, G=\frac{E}{2(1+v)}$ is the shear modulus, $c_{m}=\frac{E}{1-2 v}$ is the bulk modulus, ${ }^{t} \boldsymbol{\alpha}$ is back stress and ${ }^{t} \hat{\sigma}_{y}$ is yield stress. In all equations the deformed configuration at the beginning of the time step is marked by $t$, the deformed configuration at the end of the time step by $t+\Delta t$ and the stress-free configuration by $\tau$.

Table 4 Stress integration in case of large strain elastic-plastic deformation in isotropic plasticity

1. Modified relative strain gradient ${ }_{t}^{t+\Delta t} \overline{\boldsymbol{F}}$ is:

$$
{ }_{t}^{t+\Delta t} \overline{\boldsymbol{F}}=\left(\operatorname{det}^{t+\Delta t} \boldsymbol{F}\right)^{-\frac{1}{3} t+\Delta t} \boldsymbol{F} \text { where }{ }_{t}^{t+\Delta t} \boldsymbol{F}={ }_{t}^{t+\Delta t} \boldsymbol{J}^{T}{ }^{t} \boldsymbol{J}^{-T}
$$

2. Trial elastic left Cauchy-Green strain tensor:

${ }_{\tau}^{t+\Delta t} \overline{\boldsymbol{B}}_{*}^{E}={ }^{t+\Delta t}{ }_{t}{ }_{\tau}^{t} \boldsymbol{B}^{E t+\Delta t} \overline{\boldsymbol{F}}^{T}$

${ }_{\tau}^{t+\Delta t} \overline{\boldsymbol{B}}_{*}^{E} \rightarrow{ }_{\tau}^{t+\Delta t} \bar{\lambda}_{k^{*}}^{E},{ }_{\tau}^{t+\Delta t} \overline{\boldsymbol{p}}_{k^{*}}^{E} ; k=1,2,3$

3. Trial elastic deviatoric logarithmic strain:

$$
{ }_{t}^{t+\Delta t} \boldsymbol{e}_{*}^{{ }_{*} E}=\sum_{k} \ln \left({ }_{\tau}^{t+\Delta t} \bar{\lambda}_{k^{*}}^{E}\right){ }_{\tau}^{t+\Delta t} \overline{\boldsymbol{p}}_{k^{*}}^{E} \otimes{ }^{t+\Delta t} \overline{\boldsymbol{p}}_{k^{*}}^{E}
$$

4. Trial elastic deviatoric stress and the elastic stress radius:

$$
{ }^{t+\Delta t} \boldsymbol{S}_{*}=2 G^{t+\Delta t}{ }_{\tau} \boldsymbol{e}_{*}{ }^{E} ; \quad{ }^{t+\Delta t} \hat{\boldsymbol{S}}_{*}={ }^{t+\Delta t} \boldsymbol{S}_{*}-{ }^{t} \boldsymbol{\alpha}
$$

5. Check for yielding:

$$
\begin{aligned}
& { }^{t+\Delta t} f_{y}^{*}={ }^{t+\Delta t} \hat{\sigma}_{*}-{ }^{t} \hat{\sigma}_{y} \leq 0 \\
& \text { where }{ }^{t+\Delta t} \hat{\sigma}_{*}=\sqrt{\frac{3}{2}}\|\|^{t+\Delta t} \hat{\boldsymbol{S}}_{*} \| ;{ }^{t} \hat{\sigma}_{y}=\sigma_{y v}+C_{y}\left(M^{t} \bar{e}^{p}\right)^{n}
\end{aligned}
$$

If condition is satisfied, strain is elastic and

${ }^{t+\Delta t} \hat{\boldsymbol{S}}={ }^{t+\Delta t} \hat{\boldsymbol{S}}_{*}, \Delta \lambda=0$ go to step 7 .

6. Find effective plastic strain increment $\Delta \bar{e}^{p}$ of the function ${ }^{t+\Delta t} f_{y}\left(\Delta \bar{e}^{p}\right)=0$ :

$$
\begin{aligned}
& { }^{t+\Delta t} \bar{e}^{p}={ }^{t} \bar{e}^{p}+\Delta \bar{e}^{p} ;{ }^{t+\Delta t} \hat{\sigma}_{y}=\sigma_{y v}+C_{y}\left(M^{t+\Delta t} \bar{e}^{p}\right)^{n} \\
& \Delta \lambda=\frac{3}{2} \frac{\Delta \bar{e}^{p}}{{ }^{t+\Delta t} \hat{\sigma}_{y}} ; \hat{C}=\frac{2}{3}(1-M) n C_{y}\left({ }^{t+\Delta t} \bar{e}^{p}\right)^{n-1} \\
& { }^{t+\Delta t} \hat{\boldsymbol{S}}=\frac{{ }^{t+\Delta t} \hat{\boldsymbol{S}}_{*}}{1+(2 G+\hat{C}) \Delta \lambda} ;{ }^{t+\Delta t} \hat{\sigma}=\sqrt{\frac{3}{2}}\left\|{ }^{t+\Delta t} \hat{\boldsymbol{S}}\right\| \\
& { }^{t+\Delta t} f_{y}=\left\|{ }^{t+\Delta t} \hat{\sigma}-{ }^{t+\Delta t} \hat{\sigma}_{y}\right\|>\mathrm{TOL} \rightarrow \text { go to step } 6
\end{aligned}
$$

7. Back stress, deviatoric stress and plastic strain at the end of time step:

$$
\begin{aligned}
& { }^{t+\Delta t} \boldsymbol{\alpha}={ }^{t} \boldsymbol{\alpha}+\hat{C} \Delta \lambda^{t+\Delta t} \hat{\boldsymbol{S}} ;{ }^{t+\Delta t} \boldsymbol{S}={ }^{t} \boldsymbol{\alpha}+(1+\hat{C} \Delta \lambda){ }^{t+\Delta t} \hat{\boldsymbol{S}} \\
& { }^{t+\Delta t} \boldsymbol{e}^{p}={ }^{t} \boldsymbol{e}^{p}+\Delta \lambda^{t+\Delta t} \hat{\boldsymbol{S}}
\end{aligned}
$$

8. Elastic strains, stresses and left Cauchy-Green strain tensor for next time step:

$$
\begin{aligned}
{ }^{t+\Delta t}{ }_{\tau} \boldsymbol{e}^{{ }^{E}} & =\frac{{ }^{t+\Delta t} \boldsymbol{S}}{2 G} ;{ }^{t+\Delta t}{ }_{\tau} e_{m}^{E}=\frac{1}{3} \ln \left(\operatorname{det}^{t+\Delta t} \boldsymbol{F}\right) \\
{ }^{t+\Delta t}{ }_{\tau} \boldsymbol{e}^{E} & ={ }^{t+\Delta t} \boldsymbol{}_{\tau} \boldsymbol{e}^{E}+{ }^{t+\Delta t}{ }_{\tau}^{E} e_{m}^{E} \boldsymbol{I} \\
{ }^{t+\Delta t} \sigma_{m} & =c_{m}{ }^{t+\Delta t}{ }_{\tau} e_{m}^{E} ;{ }^{t+\Delta t} \boldsymbol{\sigma}={ }^{t+\Delta t} \boldsymbol{S}+{ }^{t+\Delta t} \sigma_{m} \boldsymbol{I} \\
{ }^{t+\Delta t} \boldsymbol{B}^{E} & =\sum_{k} \exp \left(2 \ln { }^{t+\Delta t}{ }_{\tau} \lambda_{k}^{E}\right){ }^{t+\Delta t} \overline{\boldsymbol{p}}_{k}^{E} \otimes{ }^{t+\Delta t} \overline{\boldsymbol{p}}_{k}^{E}
\end{aligned}
$$

\section{FE MODEL DESCRIPTION}

Two test specimens of thickness $0,8 \mathrm{~mm}$ and length $45 \mathrm{~mm}$ are welded with an overlap. A geometrical and material nonlinear FEM analysis of welded joint is considered using the large-strain von Mises plasticity constitutive model implemented into the PAK software [9]. The diameter of the welded joint is $6 \mathrm{~mm}$. The geometry of the modeled specimen is given in Fig. 4.
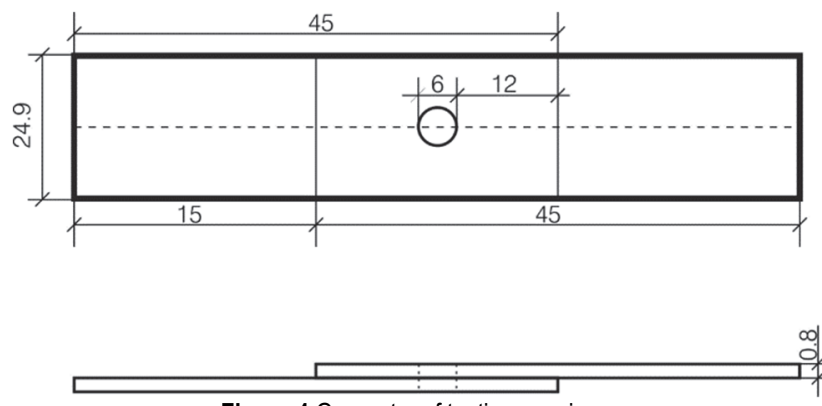

Figure 4 Geometry of testing specimen

The specimens are modeled by solid parabolic 3D elements. Due to the symmetry, one-half of the structure with proper boundary conditions is modeled. The elastic material constants for all parts of welding zones are Young modulus $E=1,98 \times 10^{5} \mathrm{MPa}$, Poisson's ratio $v=0,3$. Material constants of basic material for Ramberg-Osgood function $\sigma_{y}=\sigma_{y v}+C_{y} \bar{e}_{p}^{n}$ are determined experimentally in Eq. (7) as: $\sigma_{y v}=188,44 \mathrm{MPa}, C_{y}=357,26 \mathrm{MPa}$, and $n=$ 0,3945 . The hardening parameters of different welding zones are higher than the base material [8], so the welded zone (WZ) and the HAZ have different higher hardening parameters $C_{y}=520 \mathrm{MPa}$ and $n=1$. The FE mesh is given in Fig. 5. Different welding zones (HAZ, WZ, and BM) are presented in different colors. The analysis was done in 70 equal time steps.

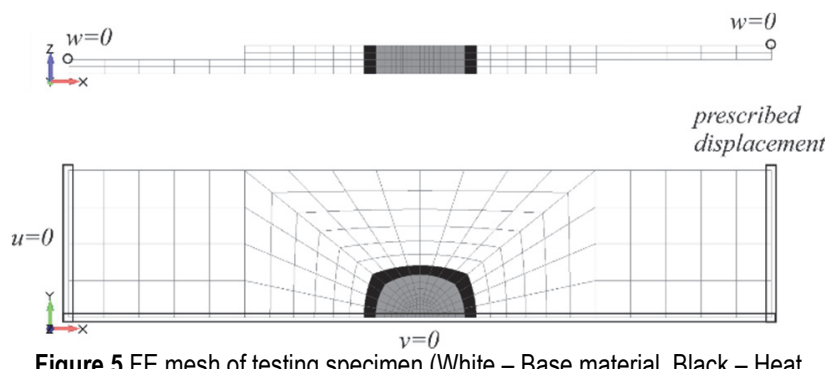

Figure 5 FE mesh of testing specimen (White - Base material, Black - Heat affected zone, Gray- Welded zone)

\section{RESULTS}

After estimation of the mechanical characteristics of steel sheet and the optimal parameters of welding, overlapping joints were examined during the uniaxial 
tension test. The scheme of experiments is given in Fig. 6 . The measured dimensions (Fig. 7) of the deformed specimen after the experiment are given in Tab. 5 .
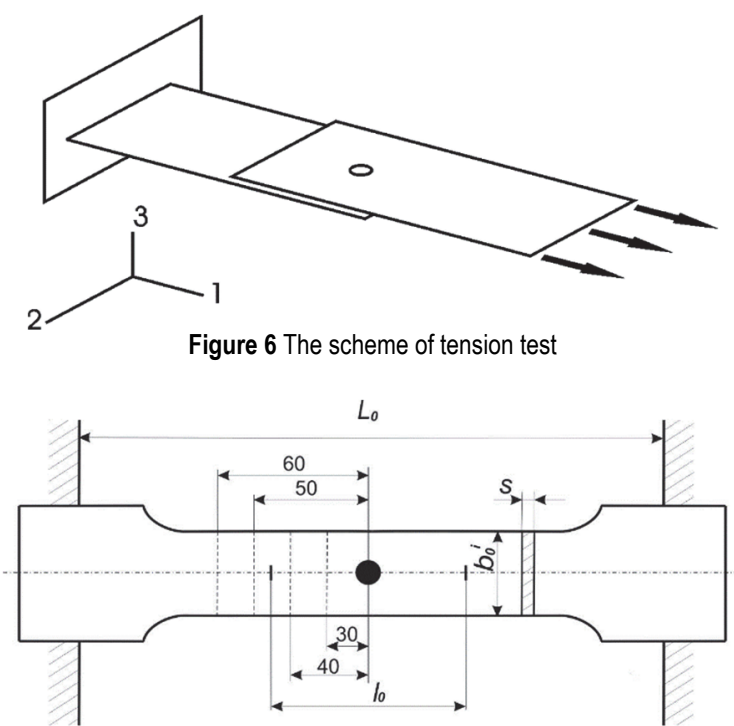

$L_{1}$

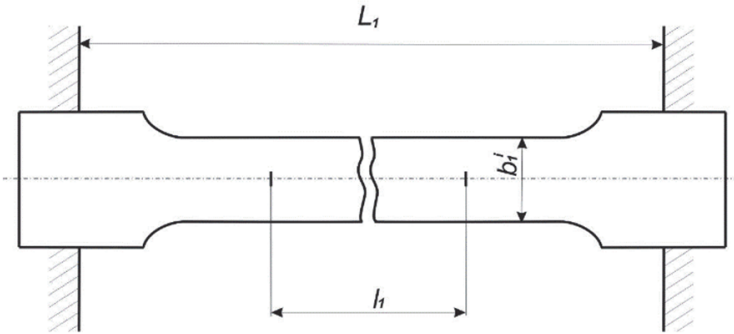

Figure 7 Measured dimensions of the specimen before and after the experiment

Comparative analysis of force-displacement dependency is given together with the numerical results in Fig. 8. The results obtained using the PAK software are presented with the dashed line and the experimental results with the continuous line. For the simulation of the failure behavior, after the elongation of $6,5 \mathrm{~mm}$, it is necessary to implement failure criteria into the algorithm. One of the possibilities suggested for the future work is a phase-field model for ductile fracture related to the plasticity model [15].

Table 5 Measured dimensions of deformed steel sheet test specimen thickness $0.8 \mathrm{~mm}$ and width $25 \mathrm{~mm}$

\begin{tabular}{|c|c|c|c|c|c|}
\hline $\begin{array}{c}\text { Maximum } \\
\text { force } F_{m} / \mathrm{N}\end{array}$ & $l_{0} / \mathrm{mm}$ & $l_{l} / \mathrm{mm}$ & $\Delta l / \mathrm{mm}$ & $b_{0} / \mathrm{mm}$ & $b_{l} / \mathrm{mm}$ \\
\hline 4488 & 79 & 85,8 & 6,8 & 24,9 & 24,67 \\
\hline
\end{tabular}

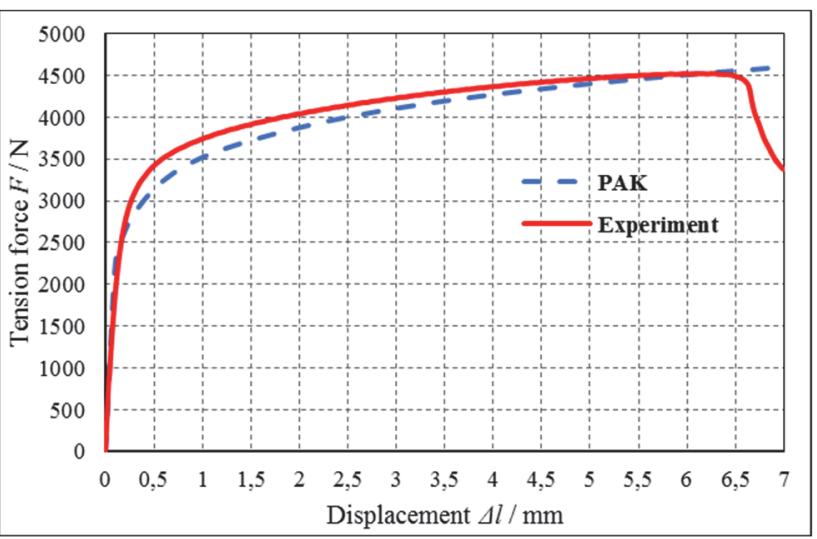

Figure 8 Force - displacement diagram for the spot welded joint

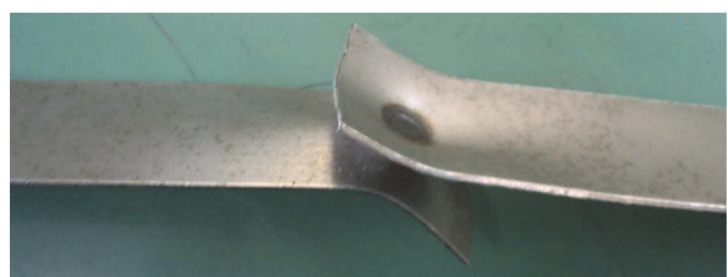

Figure 9 Deformed shape of welded joint obtained in experimental test

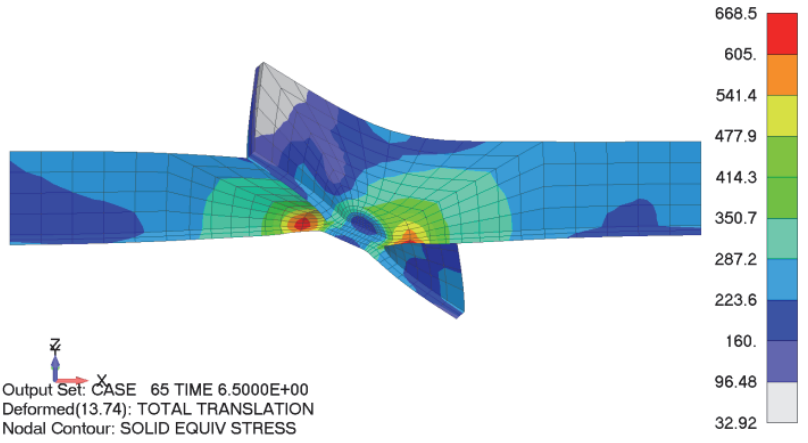

Figure 10 Numerical results for the field of effective stress in the 65th step (displacement of the loaded edge is $\Delta u=6.5 \mathrm{~mm}$ )

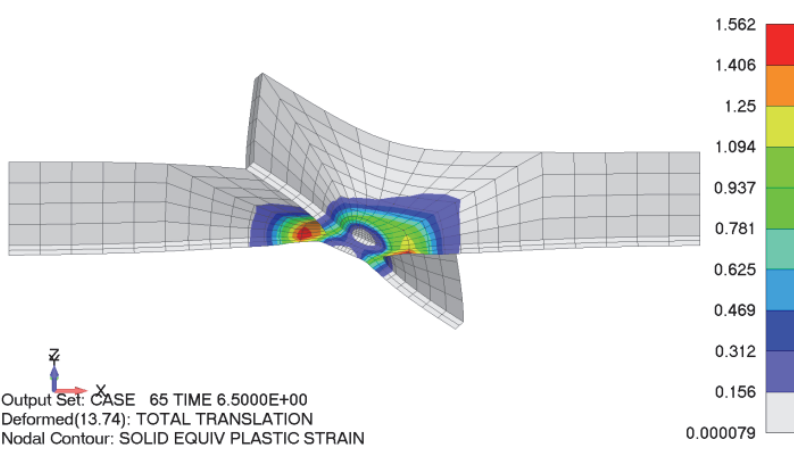

Figure 11 Numerical results for the field of plastic strain in the 65th step (displacement of the loaded edge is $\Delta u=6.5 \mathrm{~mm}$ )

The boundary conditions given in Fig. 5 are prescribed to realistically simulate experimental investigation. The deformed state of the test specimen is given in Fig. 9. The deformed configuration of FE model, and the field of effective stress and effective plastic strain are given in Fig. 10 and 11 . It can be noticed that deformed configuration is well predicted.

\section{CONCLUSIONS}

The obtained results provide a reliable prediction of crack behavior in HAZ and WZ. Comparison of the forcedisplacement results for the FE modeling and experiments tests verifies that the large-strain plasticity algorithm implemented into the in-house FEM software is a valuable tool for simulation of SW joints. The obtained results are crucial for further investigation of welded joints: failure behavior using a phase-field model for ductile fracture, behavior under the fatigue loading, and structural life assessment.

\section{Acknowledgements}

This research is financed by Ministry of Education, Science and Technological Development, Republic of Serbia, Grant TR32036. 


\section{REFERENCES}

[1] Perret, W., Schwenk, C., Ethmeier, M. R., Raphael, T. R., \& Alber, U. (2011). Case Study for Welding Simulation in the Automotive Industry. Welding in the World, 55(11-12), 8998. https://doi.org/10.1007/BF03321546

[2] Costa, H. R. M., Reis, J. M. L., Souza, J. P. B., Pacheco, P. M. C. L., Aguiar, R. A. A., \& De Barros, S. (2015). Experimental investigation of the mechanical behaviour of spot welding adhesives joints. Composite Structures, 133, 847-852. https://doi.org/10.1016/j.compstruct.2015.08.036

[3] Andersson, O., Budak, N., Melander, A., \& Palmquist, N. (2017). Experimental measurements and numerical simulations of distortions of overlap laser-welded thin sheet steel beam structures. Welding in the World, 61(5), 927-934. https://doi.org/10.1007/s40194-017-0496-z

[4] Xu, S. \& Deng, X. (2004). An evaluation of simplified finite element models for spot-welded joints. Finite Elements in Analysis and Design, 40(9-10), 175-1194. https://doi.org/10.1016/j.finel.2003.08.006

[5] Carrier, J., Markiewicz, E., Haugou, G., Lebailli, D., Leconte, N., \& Naceur, H. (2017). Influence of the heat affected zone on the dynamic behavior of a welded joint of armoured steel. International Journal of Impact Engineering, 104, 154-163. https://doi.org/10.1016/j.jijmpeng.2016.12.022

[6] Rodrigues, D., Menezes, L., \& Loureiro, A. (2004). Modelling the effect of HAZ undermatching on the crack-tip stress distribution in idealized welds. International Journal of Mechanical Sciences, 46(10), 1481-1488. https://doi.org/10.1016/j.jmecsci.2004.09.009

[7] Kong, X., Yang, Q., Li, B., Rothwell, G., English, R., \& Ren, X. J. (2008). Numerical study of strengths of spot welded joints of steel. Materials \& Design, 29(8), 1554-1561. https://doi.org/10.1016/i.matdes.2007.12.001

[8] Živković, M., Slavković, R., Kojić, M., Grujović, N., \& Vuković, M. (2005). Elastic-plastic analysis of spot-welded thin-walled structures. VIII International Conference on Computational Plasticity, CIMNE, Barcelona, Spain.

[9] Kojić, M., Slavković, R., Živković, M., \& Grujović, N. (2011). PAK-S: Program for FE Structural Analysis, University of Kragujevac, Faculty of Engineering, Kragujevac

[10] Aslanlar, S., Ogur, A., Ozsarac, U., Ilhan, E., \& Demir, Z (2007). Effect of welding current on mechanical properties of galvanized chromided steel sheets in electrical resistance spot welding. Materials \& Design, 28(1), 2-7. https://doi.org/10.1016/j.matdes.2005.06.022

[11] Jovanović, M., Adamović, D., \& Lazić, V. (2011). Tehnologija zavarivanja - priručnik, Mašinski fakultet Kragujevac, Univerzitet u Kragujevcu.

[12] Zang, S. L., Thuillier, S., Le Port, A., \& Manach, P. Y. (2011). Prediction of anisotropy and hardening for metallic sheets in tension, simple shear and biaxial tension. International Journal of Mechanical Sciences, 53(5), 338347. https://doi.org/10.1016/j.jpmecsci.2011.02.003

[13] Gronostajski, Z. (2010). The constitutive equations for fem analysis. Journal of Materials Processing Technology, 106(1-3), 40-44. https://doi.org/10.1016/S0924-0136(00)00635-X

[14] Kojić, M. \& Bathe, K.J. (2005). Inelastic Analysis of Solids and Structures ( $1^{\text {st }}$ ed.), Springer-Verlag Berlin and Heidelberg GmbH KG, Berlin, 63-71.

[15] Ambati, M., Kruse, R., \&De Lorenzis, L. (2016). A phasefield model for ductile fracture at finite strains and its experimental verification. Computational Mechanics, 57(1), 149-167. https://doi.org/10.1007/s00466-015-1225-3

\section{Contact information:}

Miroslav ŽIVKOVIĆ, PhD Full Professor (Corresponding author)

University of Kragujevac, Faculty of Engineering

Sestre Janjić 6, 34000 Kragujevac, Serbia

miroslav.zivkovic@kg.ac.rs

Marina VUKOVIĆ, MSc

University of Kragujevac, Faculty of Engineering

Sestre Janjić 6, 34000 Kragujevac, Serbia

maki.vukovic@gmail.com

Vukić LAZIĆ, PhD Full Professor

University of Kragujevac, Faculty of Engineering

Sestre Janjić 6, 34000 Kragujevac, Serbia

vlazic@kg.ac.rs

Vladimir MILOVANOVIĆ, PhD Assistant Professor

University of Kragujevac, Faculty of Engineering

Sestre Janjić 6, 34000 Kragujevac, Serbia

vladicka@kg.ac.rs

Vladimir DUNIĆ, PhD Assistant Professor

University of Kragujevac, Faculty of Engineering

Sestre Janjić 6, 34000 Kragujevac, Serbia

dunic@kg.ac.rs

\section{Dražan KOZAK, PhD Full Professor}

Mechanical Engineering Faculty in Slavonski Brod, Josip Juraj Strossmayer University of Osijek Trg Ivane Brlić-Mažuranić 2, 35000 Slavonski Brod, Croatia dkozak@sfsb.hr

Dragan RAKIĆ, PhD Assistant Professor University of Kragujevac, Faculty of Engineering Sestre Janjić 6, 34000 Kragujevac, Serbia drakic@kg.ac.rs 